\title{
EDUCAÇÃO EM ENFERMAGEM: A BUSCA DA AUTONOMIA*
}

\author{
Margareth Angelo**
}

ANGELO, M. Educaçāo em enfermagem. Rev.Eac.Enf.USP., v.28, n.1, p. 11-4 , Abril, 1994.

O propósito central da enfermagem é cuidar de pessoas, estejam elas vivenciando problemas de saúde ou nāo. A consciência desta missão de cuidar está crescendo na enfermagem e está refletida na literatura especializada, em encontros profissionais, na pesquisa e na filosofia de enfermagem. Entretanto, a consciência apenas, nāo é suficiente.

Cuidar e sua dimensão ética, deve impregnar toda a enfermagem.

Esta idéia requer um modelo de currículo, que torne legitima e central a missāo de cuidar, que é herança de todos os enfermeiros.

O cuidado como centro, é uma tendência atual, que possibilita mudanças significativas na educação em enfermagem. Esta tendência tem apontado uma renovada ênfase no papel, na missão, no compromisso e na funçāo essencial da enfermagem que é o cuidado humano, além de um retorno ao aspecto humano da enfermagem.

A ordem atual reside em mudar o foco de ensino, do treinamento para a educaçāo, da técnica para a compreensão, do conteúdo estrito para a tomada de consciència crítica.

É neste sentido, que as instituiçōes de ensino superior de enfermagem têm procurado desvendar caminhos que orientem suas açōes para a formação do chamado enfermeiro da nova era, do próximo milênio.

Muitas linhas de pensamento contribuem para a operacionalizaçảo desta nova direçāo para a educaçāo em enfermagem. E cada uma delas possibilita uma visão de ensino, de aprendizagem e de currículo.

A visão que apresento aqui, é aquela em que o currículo pode ser definido como as interaçōes que acontecem entre alunos e professores, com a intenção de que a aprendizagem ocorra. Nesta perspectiva, currículo é visto como interação. Todos os outros aspectos do curriculo como programas de atividades, atividades extracurriculares, são adjuntos das interaçóes (BEVIS; WATSON, 1989).

- Aula inaugural proferida no dia 28/2/94, na EEUSP.

- Doutora do Departamento de Enfermagem Materno-Infantil e Psiquiatrica. Presidente da Comissáo de Graduaçáo da EEUSP. 
Dentro desta linha de pensamento, surge também o conceito de aprendizagem ativa, quando são reunidos os esforços intelectuais tanto dos estudantes como dos professores. Aprendizagem ativa é necessária para o desenvolvimento do pensamento crítico, que é a marca da pessoa educada e nāo meramente treinada.

Um currículo de enfermagem deve proporcionar uma base de educaçāo para a possibilidade humana, ou seja, uma educaçāo que possibilite à pessoa pensar, agir, saber, desejar buscar, continuamente, um melhor conhecimento, buscar e duvidar da verdade, apreciar os valores que tornam a enfermagem uma atividade moral e humana. Enfim, desenvolver um compromisso com o foco da enfermagem que é o cuidado, com a enfermagem como profissão e com ela mesma, enquanto uma pessoa em processo.

Toda educaçāo, sobretudo numa universidade, tem o objetivo de graduar profissionais que sejam independentes, auto-dirigidos, auto-motivados e aprendizes constantes, com mentes questionadoras e familiaridade com o processo de aprender.

A educação deve prover ao aluno, diferentes maneiras de ver o mundo. Isto cria opçōes. Segundo JONES; BROWN (1991), a educação deve proporcionar um processo de pensamento crítico, com tudo o que isto implica, incluindo: a sensibilidade e o respeito pela vida, a habilidade de antecipar e confrontar dificuldades e problemas complexos e participar com outros no desenvolvimento de opçōes flexiveis e criativas.

A educação para ser um bem, deve ser emancipatória. Deve capacitar a pessoa a perceber, intelectualmente, os fenômenos e a dominar habilidades necessárias para lidar com eles ou investigá-los. Sem emancipação, educação é um instrumento opressivo. É uma indústria de montagem que produz enfermeiros que no máximo, seguem o "status quo". Estes enfermeiros podem provocar ondas, mas permanecem dentro de regras, enquanto vivem vidas que são circunscritas pela inflexibilidade, e carregam a inevitável estampa da banalidade e da mediocridade no seu pensar e no seu agir. (BEVIS; WATSON, 1989)

A emancipação é muito importante para a enfermagem. A educação em enfermagem ocorre num contexto social, onde o discurso oficial tem sempre favorecido a ideologia de grupos dominantes, dos quais a enfermagem está excluída. A enfermagem tem tido dificuldade em ganhar acesso ao processo decisório em niveis locais, governamentais ou centrais.

A pesquisa em enfermagem, o conhecimento e as habilidades de enfermagem, são, freqüentemente, pouco compreendidos ou valorizados em relação aos conhecimentos e habilidades de outros profissionais de saúde. Resumindo, o enfermeiro nāo tem sido, tradicionalmente, considerado como tendo poder.

A educação em enfermagem é um processo político, que tem de certo modo, reproduzido práticas tradicionais que reforçam certas contradiçōes vivenciadas pelo estudante, entre conhecimento recebido em sala-de-aula e aquele que deriva de suas experiências clínicas. A experiência no ensino de enfermagem tem mostrado que os ideais profissionais de autonomia, poder e 
prática reflexiva, parecem ser realidades diferentes na sala-de-aula e na prática clínica.

Nāo é apenas na sala-de-aula que se vivencia a educação em enfermagem. Pode-se aprender em muitos ambientes diferentes. E é nessa diversidade de situaçōes, que se notam as diferentes realidades.

As instituiçōes de saúde e de educação são estruturas hegemônicas, uma vez que as idéias, valores e crenças que possuem, representam o controle social daquela cultura e influenciam a consciência das pessoas ali presentes, que passam a aceitar esta visão de mundo particular, como senso comum (CLARE, 1993). Eu aponto esta questāo em especial, para afirmar que o conhecimento de enfermagem não depende apenas dos modelos de ensino ou de prática instituídos. Este conhecimento depende e sofre a interferéncia do contexto histórico, social e político e nāo está separado de interesses pessoais, sociais e políticos.

O conhecimento é socialmente construído. Ele pode acontecer através de um processo de questionamento sistemático no qual o aluno pratica a observação, descriçāo, análise e discussāo do contexto institucional e da prática com os quais interage. O exercício de refletir sobre as próprias açōes, explicar o que fez e porque fez, e apresentar sua metodologia de ação, ajuda a ver possíveis caminhos abertos para resolver problemas profissionais e pessoais.

Com isto, quero dizer que os alunos podem e devem ser participantes ativos na criação e interpretação dos ambientes sociais e, conseqüentemente, do processo de sua própria aprendizagem.

Os responsáveis pela educaçāo em enfermagem, a nível mundial, vêm tentando ultrapassar as condiçōes que restringem o poder do enfermeiro. $O$ caminho para isto, parece estar ficando mais claro agora. O exercício da autonomia e auto-determinaçāo do enfermeiro se dá quando ele domina o conhecimento em seu campo, quando ele cria conhecimento sobre sua prática e quando ele usa o conhecimento de maneira apropriada no cuidado de saúde. Para isto, não basta a organizaçāo de um currículo, com disciplinas, aparentemente, perfeitas em termos de conteúdo, é preciso também a implementaçāo de condiçōes que possibilitem a aprendizagem plena.

Tendo este propósito como foco, a EEUSP após um longo e intenso processo de trabalho, conseguiu organizar um novo currículo, que tem início este ano. O novo currículo contém alguns elementos que representam o que hoje se denomina a revoluçāo de currículo de enfermagem. Esta revoluçāo como sugere COHEN. (1993), está direcionada a alterar os modelos patriarcais de dominaçáo e controle, para um de emancipação.

Os elementos de maior destaque no nosso currículo são o processo de cuidar como eixo central e a múltipla visão de realidade, que apóiam a crença da enfermagem estar alicerçada em múltiplas formas de conhecimento. Estes elementos, somados à dimensão pretendida à relação professor-aluno, que transforme um relacionamento tradicional de poder centrado no professor, e estimule um de responsabilidade compartilhada, podem resultar em condi- 
çōes facilitadoras da aprendizagem de enfermagem e que permitirão aos alunos assumirem a máxima responsabilidade por sua própria aprendizagem.

Este currículo não é o caminho, mas a possibilidade de caminhar, de vivenciar uma aprendizagem que pode ser significativa. Lembrando ROSENBERG. (1987), na busca da renovação será preciso passar por roteiros diversos, que incluem as atitudes dos professores, as contingèncias sociais e políticas, o nível de facilitação em sala-de-aula, o clima psicológico da escola, os métodos didáticos, o auto-conhecimento tanto do educando como do educador.

Acredito que num processo partilhado de construção e avaliação constante, alunos e professores encontraráo juntos, situaçōes e lugares para explorar, conhecer e interagir como um todo, aprenderāo juntos e quem sabe juntos, descobrirão processos de melhor aprender enfermagem e a té agirão para transformar as estruturas sociais que limitam a autonomia da enfermagem.

Neste sentido, vejo neste novo currículo, nas interaçōes conseqüentes a ele, uma possibilidade, nảo apenas de legitimar o cuidado como propósito central da enfermagem, mas também de ser um recurso para educar pessoas que, efetivamente, sintam-se comprometidas a fortalecer a enfermagem como profissão. Profissão esta, vivida por pessoas que pretendem exercitar, plena e responsavelmente, sua autonomia.

\section{REFERÊNCIAS BIBLIOGRÁFICAS}

BEVIS, E. O.; WATSON, J. A caring curriculum: a new pedagogy for nursing. New York, National League for Nursing. 1989.

CLARE, J. A challenge to the rhetoric of emancipation: recreating a professional culture. J. Adv. Nurs, v. 18, n. 7, p. 1033-8, 1993.

COHEN, J. A. Caring perspectives in nursing education: liberation, transformation and meaning. J. Adv. Nur.. v.18, n.4, p.621-6,1993.

JONES, S. A.; BROWN, L. N. Critical thinking impact on nursing education. J Adv. Nurs, v.16, n.3, p.529.533, 1991.

ROSENBERG, R. L. Aprendizagem sobre o aprender: ० fio da sintonia. Rev.USP, n.4, p.53-64, março, 1987 